\title{
AZIMUTHAL ANISOTROPY OF SURFACE WAVES AND THE POSSIBLE TYPE OF THE SEISMIC ANISOTROPY DUE TO PREFERRED ORIENTATION OF OLIVINE IN THE UPPERMOST MANTLE BENEATH THE PACIFIC OCEAN
}

\author{
Ichiro KAWASAKI and Fujitoshi Kon'NO* \\ Department of Earth Sciences, Toyama University, \\ Toyama, Japan \\ (Received March 7; Revised August 6)
}

The group velocities of surface waves in the period range 22-89 s were measured to retrieve the anisotropy pattern of the surface wave velocities in the Eastern Pacific Ocean. WWSSN long period records at KIP, Hawaii, from ridge events in the Gulf of California, the East Pacific rise, and the Easter Island Cordillera were used to cover propagation directions $\mathrm{N} 60^{\circ} \mathrm{E}-\mathrm{N} 140^{\circ} \mathrm{E}$. These station and epicenters are in very favorable positions to minimize the effects of the lateral heterogeneity owing to ocean floor ages. The fast direction of the Rayleigh wave group velocity is normal to ridge, showing 3-5\% azimuthal anisotropy. The Love wave group velocity shows little azimuthal anisotropy.

A model of a possible type of preferred orientation of constituent olivine beneath the Pacific Ocean is proposed, based on the elastic constants and the petrofabrics of dunite from Hidaka, Hokkaido, Japan, and that of olivine nodules in the ophiolite complex from the Bay of Islands and Oman. In this model, $a$-axis is concentrated along a particular direction and $b$ - and $c$-axes form a girdle. Elastic constants of the model are $C_{11}=2.44, C_{22}=C_{33}=2.05$, $C_{12}=C_{13}=0.72, C_{23}=0.67, C_{44}=0.69$, and $C_{5 b}=C_{68}=0.75\left(10^{12} \mathrm{dyn} \cdot \mathrm{cm}\right)$, where $X_{1}$-axis, or the direction of the $a$-axis concentration, is normal to ridge and $X_{3}$-axis is vertical.

If we assume that the type of the preferred orientation is an age-independent property of suboceanic lithosphere, this model can explain the overall features of the large-scale anisotropy in the Pacific Ocean: the azimuthal anisotropy of surface wave velocities as described above; the SH-SV anisotropy of surface waves of about $0.15 \mathrm{~km} / \mathrm{s}$; the $P_{n}$ anisotropy of $7.9 \mathrm{~km} / \mathrm{s}$ to $8.6 \mathrm{~km} / \mathrm{s}$; the high $S_{n}$ velocity of about $4.8 \mathrm{~km} / \mathrm{s}$; and the ScS polarization anisotropy.

\section{Introduction}

Since the first recognition of large-scale anisotropy by HEss (1964), there has been much firm seismological evidence for the large-scale anisotropy. Following

* Present address: Nippon Schlumberger K. K., Shinjuku-ku, Tokyo, Japan 
Hess (1964), the $P_{n}$ anisotropy was reported by Morris et al. (1969), RAITt et al. (1969), KeEn and Barrett (1971), OKada et al. (1978), and Shimamura et al. (1983). The surface wave anisotropy including so-called SH-SV anisotropy and the azimuthal variation of propagation velocity were widely recognized by McEvilly (1964), Kaminuma (1966), Forsyth (1975), Schlue and Knopoff (1977), YU and Mitchell (1979), and Mrtchell and YU (1980). Recently, we have also had evidence from free oscillations (ANDERSON and DzIEwONSKI, 1982). Petrofabric observations of outcrop nodules presumed to have been in the uppermost mantle showed clear anisotropy as investigated by KASAHARA (1968), Peselnick et al. (1974), Christensen and Salisbury (1979) and Christensen and SMEWING (1981).

The large-scale anisotropy is believed to be exclusively due to the preferred orientation of crystallographic axes of constituent olivine in the uppermost mantle. This large-scale anisotropy should be directly connected with the formation and the geodynamic processes of plates. Therefore, it is of great importance to resolve the variety of seismological observations of the large-scale anisotropy in terms of the preferred orientation of the constituent olivine. Several hypotheses have been suggested for the type of the preferred orientation (HESS, 1964; FraNCIS, 1969; CRAMPIN and BAMFORD, 1977; KAWASAKI, 1982). However, some observational facts seem to be inconsistent with the nature of the models based on single crystal olivine (SCO) or a mixture (MIX) of the SCO and isotropic or transversely isotropic materials. In particular, ForsYTH's (1975) observation of the little (less than $1 \%$ ) anisotropy of Love waves was difficult to explain by any of the previously proposed hypotheses. These disparities have been worrying seismologists interested in the large-scale anisotropy in the past decade.

One of our purposes is to retrieve the azimuthal anisotropy pattern of surface waves in the Eastern Pacific Ocean, the eastern part of the Pacific plate, which seems to have been the most controversial among observations on the large-scale anisotropy. The second purpose is to trace the variety of the observations back to the possible form of the constituent olivine in the uppermost mantle beneath the Pacific Ocean.

\section{Data and the Method}

We found 36 events from sorting EDF tapes (USGS) for ridge events of magnitudes 5.8-7.0 for the period range 1963-1978 and the latitude range N35 $-\mathrm{S} 40^{\circ}$ along the eastern boundary of the Pacific plate: the Gulf of California, the East Pacific rise, and the Easter Island Cordillera. Scanning WWSSN long period records at KIP, Hawaii, we excluded 22 events because of lack of records and small amplitude surface wave traces compared with long period microseisms which are continuously large at KIP. Long period records of the remaining 14 events were digitized.

The group velocities were calculated by the use of the multi-filter technique 
of DzIEwONSKI et al. (1969) with the proper Hanning window, the beginning and the end of which were the arrival times of surface waves of group velocities $3.5 \mathrm{~km} / \mathrm{s}$ and $4.2 \mathrm{~km} / \mathrm{s}$ for Rayleigh waves, and $4.0 \mathrm{~km} / \mathrm{s}$ and $4.8 \mathrm{~km} / \mathrm{s}$ for Love waves, respectively. In some cases, the window was extended further, based on our judgement of the duration of the fundamental mode Rayleigh and Love waves. Other details of the method used in this paper are the same as described in YoSHIDA (1978). We adopted only group velocities obtained with single point "99", which denotes the maximum of the log normalized amplitude of the instantaneous amplitude spectra (see DzIEwONSKI et al., 1969 or YOSHIDA, 1978) and averaged out 3 group velocities in the adjacent periods. Origin times and epicenters determined by the USGS were used. Even if the origin times and the epicenters had errors of $15 \mathrm{~s}$ or $50 \mathrm{~km}$, respectively, they possibly yield errors of about $0.04 \mathrm{~km} / \mathrm{s}(\sim 1 \%)$ to the group velocity estimations. Because the errors of the USGS hypocenters are considered to be not so large, the errors have no effects on the conclusions in the later sections.

Corrections for anelasticity and sphericity of the earth are about $1 \%$ of surface wave velocities and cannot be neglected when inverting them into the velocity structure of the earth's interior. However, these corrections are not made to the observed group velocities in the present study because these corrections are independent of a length and an azimuth of a propagation path of the surface waves analyzed and are not necessary for our purpose of seeing anisotropy patterns of the surface wave group velocities in the Pacific Ocean.

It was pointed out (e.g., THATCHER and BRUNE, 1969) that the higher mode contamination possibly yields serious error to the group velocity estimation for the Love waves in the period range of several tens of seconds for the oceanic structure having a distinct low velocity zone (LVZ). However, if we consider the earth model such as the PREM (DZIEWONSKI and ANDERSON, 1981) with a less distinct $L V Z$, relative excitations of the higher mode surface waves are likely to be small (FoRSYTH, 1975). For this reason, we neglected the higher mode contamination of the Love waves.

Figure 1 displays epicenters (Table 1) and azimuthal coverage of propagation paths of the surface waves for which dispersion curves (Tables 2 and 3) were finally obtained with satisfactory quality. Isochrons of ocean floor age are simply trending north-south (PITMAN et al., 1974) in this area. Since the propagation paths contain ocaen floors of various ages in nearly the same ratios in this setting of the station KIP and the epicenters, the effects of lateral heterogeneity due to the age of the ocean floor are minimized. The azimuthal coverage could not be extended further because of abrupt change of the trend of the isochrons outside the area.

\subsection{The azimuthal anisotropy of surface waves}

Figures 2 and 3 are azimuthal variations of average group velocities of Rayleigh (Table 2) and Love waves (Table 3 ) for three period ranges indicated. For periods shorter than $30 \mathrm{~s}$, the group velocity scattered widely and was not used to reveal 
Table 1. List of ridge events along the Gulf of California, the East Pacific rise, and the Easter Island Cordillera, for which satisfactory dispersion curves at KIP, Hawaii, were obtained.

\begin{tabular}{|c|c|c|c|c|c|c|c|c|c|c|c|c|c|}
\hline \multirow{2}{*}{ No. } & \multicolumn{3}{|c|}{ Date } & \multicolumn{3}{|c|}{ Origin time } & \multirow{2}{*}{ Lat. $(0)$} & \multirow{2}{*}{ Long. $\left({ }^{\circ}\right)$} & \multirow{2}{*}{$\begin{array}{l}\text { Depth } \\
(\mathrm{km})\end{array}$} & \multirow{2}{*}{$M_{\mathrm{s}}$} & \multirow{2}{*}{$m_{\mathrm{b}}$} & \multirow{2}{*}{$\Delta\left(^{\circ}\right)$} & \multirow{2}{*}{$\phi\left({ }^{\circ}\right)$} \\
\hline & Yr & M & D & $\mathrm{h}$ & $\min$ & $\mathrm{s}$ & & & & & & & \\
\hline 1 & 1964 & 10 & 12 & 21 & 55 & 33.2 & $31.30 \mathrm{~S}$ & $110.80 \mathrm{~W}$ & 25 & 6.0 & & 69.5 & 138.0 \\
\hline 2 & 1965 & 12 & 06 & 11 & 34 & 51.9 & $19.00 \mathrm{~N}$ & $107.10 \mathrm{~W}$ & 20 & 5.9 & & 47.6 & 83.4 \\
\hline 3 & 1966 & 08 & 07 & 17 & 36 & 26.7 & $31.80 \mathrm{~N}$ & 114.5 & 16 & 6.3 & & 40.0 & 65.6 \\
\hline 4 & 1968 & 08 & 09 & 03 & 08 & 04.2 & $22.40 \mathrm{~S}$ & $113.00 \mathrm{~W}$ & 33 & 5.4 & 5.8 & 62.0 & 132.2 \\
\hline 5 & 1969 & 04 & 22 & 06 & 31 & 57.5 & $26.77 \mathrm{~S}$ & 114.1 & 33 & 5.6 & 6.2 & 64.3 & 136.6 \\
\hline 6 & 1971 & 02 & 09 & 14 & 00 & & & & 08 & 6.2 & 6.5 & 37.0 & 60.8 \\
\hline 7 & 1973 & 09 & 21 & 07 & 13 & 34.0 & $04.39 \mathrm{~S}$ & $102.00 \mathrm{~W}$ & 33 & 6.1 & 6.0 & 60.6 & 108.4 \\
\hline 8 & 1974 & 05 & 10 & 08 & 12 & 05.0 & $04.37 \mathrm{~S}$ & $102.11 \mathrm{~W}$ & 33 & 6.1 & 6.0 & 60.5 & 108.4 \\
\hline 9 & 1974 & 05 & 31 & 14 & 04 & 59.9 & $27.23 \mathrm{~N}$ & $111.24 \mathrm{~W}$ & 33 & 5.3 & 6.3 & 42.8 & 72.6 \\
\hline 10 & 1975 & 09 & 11 & 21 & 59 & 57.2 & $06.99 \mathrm{~N}$ & $104.28 \mathrm{~W}$ & 33 & 5.8 & 6.2 & 53.8 & 97.2 \\
\hline 11 & 1979 & 01 & 26 & 10 & 04 & 32.0 & $17.41 \mathrm{~N}$ & $100.88 \mathrm{~W}$ & 41 & 5.8 & 6.6 & 53.7 & 83.6 \\
\hline
\end{tabular}

$\Delta$ is an epicentral distance. $\phi$ is an azimuthal direction of the epicenter measured clockwise from the north.

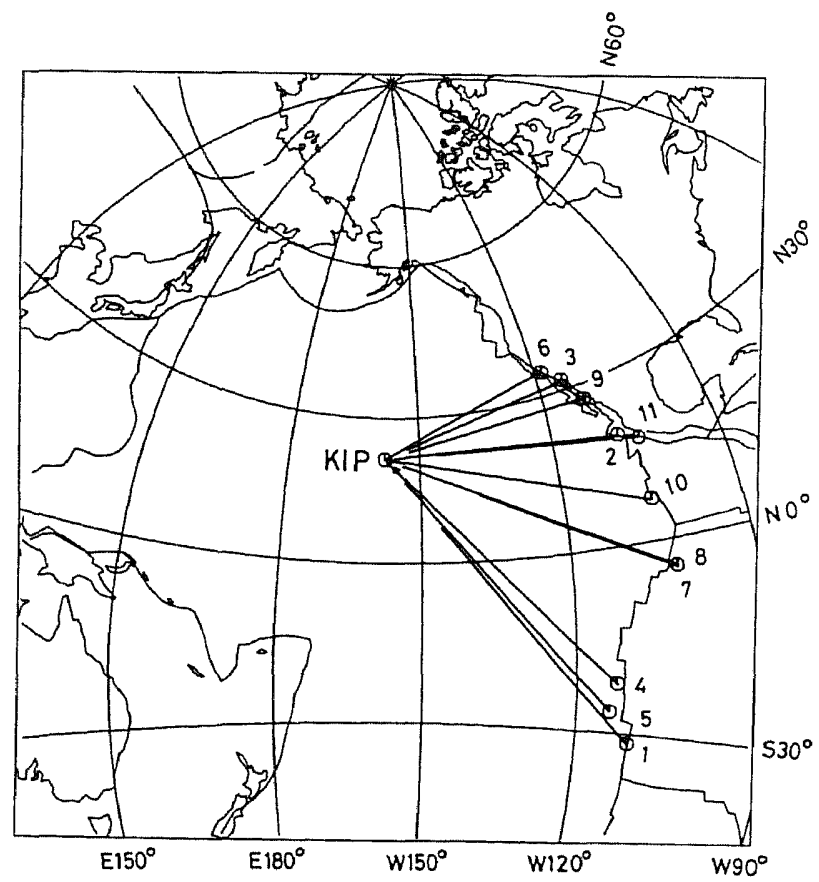

Fig. 1. Lambert equal area projection of the Pacific Ocean. Origin of the projection is at KIP. This shows azimuthal coverage of propagation paths, for which satisfactory dispersion curves were obtained. Numerals are event No. in Table 1.

the anisotropy pattern. The scatter may be attributed partly to inaccuracy of the group velocity estimation due to the long period microseisms, partly to lateral heterogeneity in very shallow structure including depths of the ocean floor, and partly 
Table 2. Observed group velocities of Rayleigh waves.

\begin{tabular}{|c|c|c|c|c|c|c|c|c|c|c|}
\hline \multirow{2}{*}{$\begin{array}{l}\text { Period } \\
\text { (s) }\end{array}$} & \multicolumn{10}{|c|}{ Event No. } \\
\hline & 1 & 3 & 4 & 5 & 6 & 7 & 8 & 9 & 10 & 11 \\
\hline 22.8 & 3.62 & 3.66 & 3.70 & 3.65 & 3.73 & 3.78 & 3.92 & 3.62 & & 4.18 \\
\hline 24.3 & 3.60 & 3.78 & 3.66 & 3.64 & 3.74 & 3.70 & 3.99 & 3.63 & & 4.16 \\
\hline 25.9 & 3.64 & 3.88 & 3.68 & 3.61 & 3.78 & 3.66 & 4.02 & 3.66 & & 4.14 \\
\hline 27.7 & 3.70 & 3.98 & 3.74 & 3.67 & 3.82 & 3.71 & 4.06 & 3.75 & & 4.14 \\
\hline 29.5 & 3.75 & 4.08 & 3.81 & 3.72 & 3.86 & 3.76 & 4.09 & 3.84 & & 4.11 \\
\hline 31.5 & 3.83 & 4.07 & 3.89 & 3.81 & 3.92 & 3.87 & 4.06 & 3.91 & & 4.09 \\
\hline 33.6 & 3.91 & 4.05 & 3.97 & 3.90 & 3.98 & 3.98 & 4.02 & 3.98 & & 4.08 \\
\hline 35.9 & 3.93 & 4.05 & 3.98 & 3.99 & 4.01 & 4.06 & 4.03 & 4.04 & 4.10 & 4.08 \\
\hline 38.3 & 3.92 & 4.05 & 3.97 & 3.98 & 3.99 & 4.06 & 4.02 & 4.05 & 4.09 & 4.04 \\
\hline 40.9 & 3.92 & 4.05 & 3.96 & 3.98 & 3.98 & 4.05 & 4.00 & 4.04 & 4.06 & 4.02 \\
\hline 43.6 & 3.90 & 4.03 & 3.95 & 3.96 & 4.02 & 4.04 & 3.98 & 4.02 & 4.03 & 4.00 \\
\hline 46.6 & 3.89 & 4.02 & 3.95 & 3.93 & 4.04 & 4.03 & 3.97 & 4.01 & 4.01 & 3.95 \\
\hline 49.7 & 3.88 & 4.00 & 3.98 & 3.91 & 4.00 & 4.01 & 3.96 & 3.99 & 3.97 & 3.88 \\
\hline 53.0 & 3.88 & 3.98 & 3.95 & 3.88 & 3.99 & 3.99 & 3.95 & 3.96 & 3.97 & 3.85 \\
\hline 56.6 & 3.86 & 3.95 & 3.92 & 3.85 & 3.97 & 3.97 & 3.94 & 3.92 & 3.98 & 3.84 \\
\hline 60.4 & 3.86 & 3.92 & 3.90 & 3.83 & 3.88 & 3.95 & 3.92 & 3.90 & 3.96 & 3.86 \\
\hline 64.4 & 3.85 & 3.90 & 3.86 & 3.82 & 3.78 & 3.93 & 3.91 & 3.89 & 3.94 & 3.86 \\
\hline 68.8 & 3.82 & 3.89 & 3.82 & 3.80 & 3.74 & 3.91 & 3.89 & 3.90 & 3.90 & 3.80 \\
\hline 73.4 & 3.80 & 3.88 & 3.82 & 3.78 & 3.71 & 3.90 & 3.88 & 3.92 & 3.84 & 3.74 \\
\hline 78.3 & 3.77 & 3.85 & 3.81 & 3.77 & 3.67 & 3.89 & 3.87 & 3.91 & 3.76 & \\
\hline 83.6 & 3.73 & 3.81 & 3.78 & 3.73 & 3.64 & 3.89 & 3.86 & 3.89 & 3.70 & \\
\hline 89.2 & 3.69 & 3.74 & 3.76 & 3.68 & 3.63 & 3.88 & 3.84 & 3.83 & 3.65 & \\
\hline
\end{tabular}

Unit: $\mathrm{km} / \mathrm{s}$

Table 3. Observed group velocities of Love waves.

\begin{tabular}{lccccccc}
\hline \multirow{2}{*}{ Period (s) } & \multicolumn{7}{c}{ Event ${ }_{v}$ No. } \\
\cline { 2 - 8 } & 2 & 4 & 5 & 7 & 9 & 10 & 11 \\
\hline 35.9 & 4.42 & 4.40 & 4.39 & 4.34 & 4.42 & 4.36 & 4.35 \\
38.3 & 4.40 & 4.42 & 4.40 & 4.34 & 4.42 & 4.40 & 4.38 \\
40.9 & 4.40 & 4.42 & 4.40 & 4.35 & 4.43 & 4.43 & 4.40 \\
43.6 & 4.39 & 4.43 & 4.40 & 4.37 & 4.44 & 4.45 & 4.41 \\
46.6 & 4.40 & 4.43 & 4.41 & 4.39 & 4.45 & 4.46 & 4.43 \\
49.7 & 4.43 & 4.44 & 4.41 & 4.41 & 4.45 & 4.46 & 4.44 \\
53.0 & 4.46 & 4.44 & 4.42 & 4.42 & 4.44 & 4.44 & 4.44 \\
56.6 & 4.48 & 4.44 & 4.42 & 4.43 & 4.42 & 4.42 & 4.42 \\
60.4 & 4.50 & 4.44 & 4.42 & 4.43 & 4.41 & 4.42 & 4.41 \\
64.4 & 4.51 & 4.44 & 4.42 & 4.42 & 4.40 & 4.41 & 4.39 \\
68.8 & 4.50 & 4.44 & 4.42 & 4.42 & 4.40 & 4.40 & 4.39 \\
73.4 & 4.49 & 4.44 & 4.42 & 4.42 & 4.40 & 4.39 & 4.39 \\
78.3 & 4.49 & 4.44 & 4.42 & 4.41 & 4.40 & 4.38 & 4.41 \\
83.6 & 4.49 & 4.43 & 4.42 & 4.40 & 4.41 & & 4.42 \\
89.2 & 4.50 & 4.42 & 4.41 & 4.40 & 4.42 & & \\
\hline
\end{tabular}

Unit: $\mathrm{km} / \mathrm{s}$ 
RAYLEIGH WAVE GROUP VELOCITY
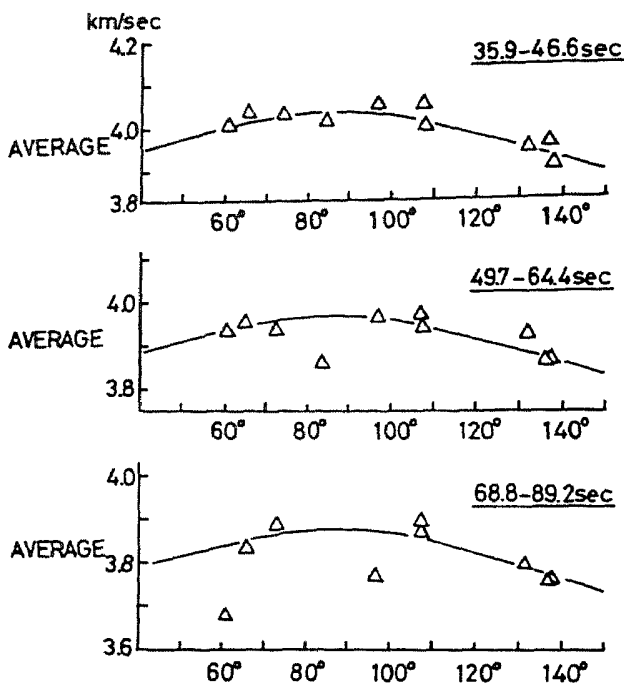

Fig. 2. Azimuthal distribution of Rayleigh wave group velocities averaged over the period range indicated. Solid lines are sinusoids which are anisotropy pattern of QSV-wave velocity of the possible model for the preferred orientation of the constituent olivine proposed in the later section of this paper. Absolute value of the sinusoids are arbitrary.

to higher mode contamination. For the period range longer than $30 \mathrm{~s}$, there seems to be no effect of the very shallow structure, such as water depths and thicknesses of oceanic crust, on the anisotropy pattern. For periods longer than $70 \mathrm{~s}$, the data scatter again. This may be due to poorly dispersed wave train because of short path lengths $\left(50^{\circ}-70^{\circ}\right)$.

Figure 2 indicates that the Rayleigh waves are fastest parallel to the trend $\left(\mathrm{N} 80^{\circ} \mathrm{E}\right)$ of the fracture zones in the Eastern Pacific Ocean. The amount of anisotropy is $0.1-0.15 \mathrm{~km} / \mathrm{s}$. According to MITCHELL and YU (1980), the Rayleigh wave group velocities at a period of $40 \mathrm{~s}$ are $4.001 \mathrm{~km} / \mathrm{s}$ and $4.077 \mathrm{~km} / \mathrm{s}$ in the regions of ocean floor ages of 20-50 m.y. and 50-100 m.y., respectively. The difference between them is $0.076 \mathrm{~km} / \mathrm{s}$. Thus, the observed amount of the anisotropy of $0.1-0.15 \mathrm{~km} / \mathrm{s}$ seems to be too large to account for by lateral heterogeneity, as far as we are within a scope of plate-thickening hypothesis as derived by YosHII (1975). If we interpret the anisotropy pattern by the $\sin (2 \theta)$ term following the result of FORSYTH (1975) in this area, it has the anisotropy of 3-5\%.

Figure 3 shows little anisotropy of the Love waves. The Love waves are the slowest parallel to the fracture zones. The present authors think that we have confirmed Forsyth's discovery by Figs. 2 and 3. Note that the definition of the amount of the anisotropy in this paper is as $2 \times\left(V_{\max }-V_{\min }\right) /\left(V_{\max }+V_{\min }\right)$, which is twice as many as Forsyth's (1975) definition. 
LOVE WAVE GROUP VELOCITY
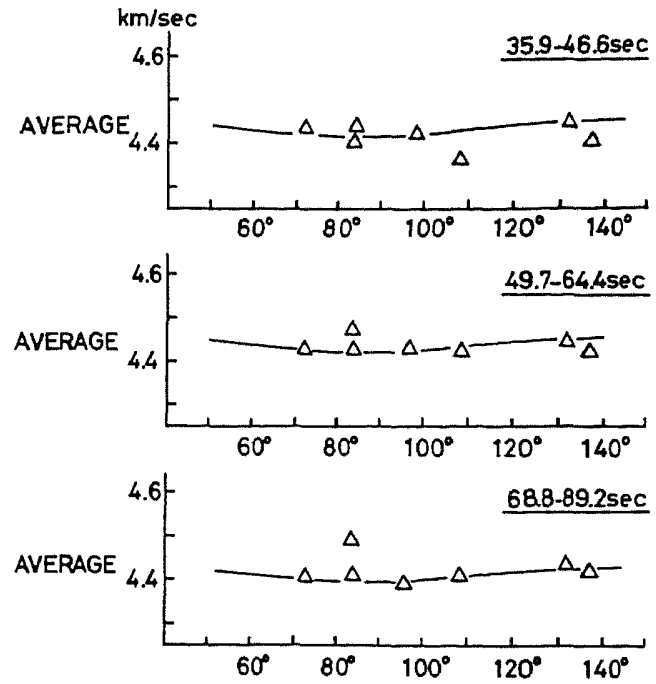

Fig. 3. Azimuthal distribution of Love wave group velocities averaged over the period range indicated. Solid lines are the same as those in Fig. 2 except for QSH-wave velocity.

If we consider the SCO for the reference model of the possible from of constituent olivine and we assume $a$-axis normal to ridge, the azimuthal anisotropy of quasi body waves (CRAMPIN, 1976), the QSV and the QSH, amounts to 0.4 $0.5 \mathrm{~km} / \mathrm{s}$ (KASAHARA et al., 1968), respectively. The observed anisotropy of the Rayleigh waves is about one-third of that required by the anisotropy pattern of the QSV of the SCO model. On the other hand, the QSH waves have the same group velocity every $90^{\circ}$ in planes of symmetry of the SCO. Thus, the SCO requires that the anisotropy patterns of the QSH and, consequently, the Love waves should be represented by $\sin (4 \theta)$ term. In this constraint, the azimuthal anisotropy of the Love waves of $\sim 1 \%$ means a change of group velocity of $0.04-0.05 \mathrm{~km} / \mathrm{s}$ every $45^{\circ}$ of azimuth. Although we do not give statistical discussion to the amount of the observed azimuthal anisotropy of the Love waves because of small azimuthal coverage, it can be said from Fig. 3 that a group velocity change with the azimuth change of $45^{\circ}$ is $0.05 \mathrm{~km} / \mathrm{s}$ at the most and the anisotropy of the Love waves should be $1 \%$ or less.

The observed anisotropy for the Love waves is small, which is contradictory to the SCO model. As far as we are concerned with the SCO or the MIX, we cannot resolve the disparity between large $\mathrm{P}_{\mathrm{n}}$ anisotropy and the small anisotropy of the Love waves. On the other hand, the observations are well-interpreted (Figs. 2 and 3) by sinusoids which are the anisotropy pattern of velocities of the QSV and QSH waves of the possible model HDM proposed in the later section for the preferred orientation of the constituent olivine. Absolute values of the QSV- 

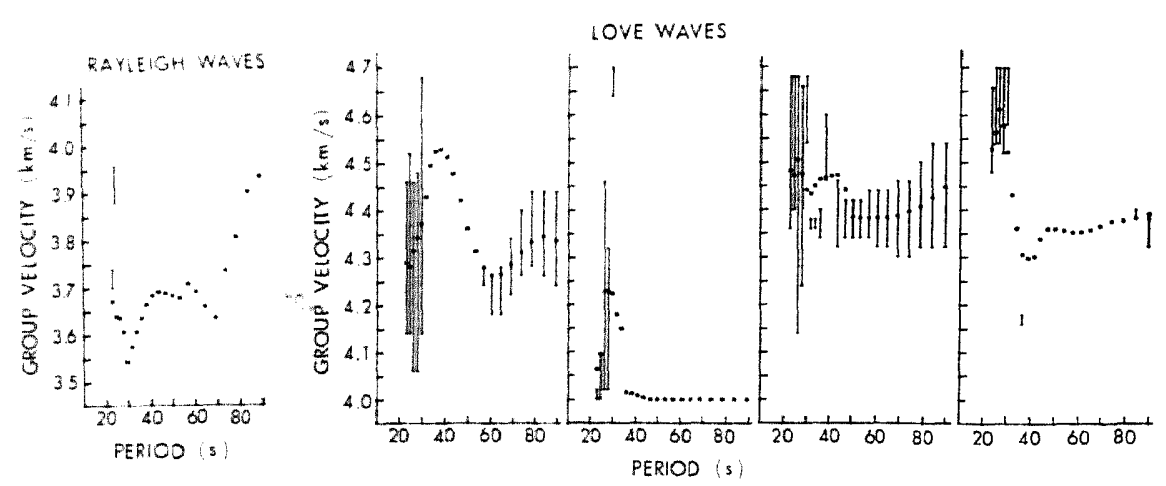

Fig. 4. Dispersion curves which show abnormal behavior. Bars indicate a range of point "99", meaning of which is given in the text and in YOSHIDA (1978), and dots are group velocities averaged over five adjacent periods.

and QSH-wave velocities specifying the sinusoids are arbitrary.

In this paper, a simple comparison is being made between azimuthal anisotropy patterns of the surface wave observations and the quasi body waves, the QSH and the QSV. In an exact sense, the anisotropy pattern of the observations must be compared with that of theoretical generalized surface waves. However, if we consider a lithosphere of a thickness of about several tens of kilometers consisting of the oriented olivine with a crust of $5 \mathrm{~km}$ thickness, the nature of surface wave dispersion in the periods around 40-50 s should be controlled principally by the statistical orientation of the constituent olivine. The anisotropy patterns of group velocities of the Rayleigh and the Love waves must be nearly equal to those of group velocities of the quasi body waves, the QSV and the QSH, respectively, to the first order approximation. This is the reason for the simple comparison. Strict comparison will be made in the next paper.

Dispersion curves averaged over azimuths show a general trend similar to those in the Pacific Ocean of ages 50-80 m.y. of YoshIDA (1978).

Some dispersion curves showed abnormal behavior as illustrated in Fig. 4. We excluded such dispersion curves in the analysis and included one additional event (No. 11 in Table 1). The reason for such abnormal behavior mainly of the Love waves may be ScS contamination which arrives at KIP with apparent velocities $4.1-4.5 \mathrm{~km} / \mathrm{s}$ at epicentral distances $40^{\circ}-45^{\circ}$.

\subsection{A model of the possible form of constituent olivine}

As reviewed earlier in this paper, we have had much firm evidence for the large-scale anisotropy. A good example is SHimamura et al.'s (1983) long-shot experiments in the Northwest Pacific Ocean. However, even their results do not contain details as to represent the azimuthal variation of the $P_{n}$ velocity. The accent of their paper is the amount of the large $P_{n}$ anisotropy, ranging from 7.9 $\mathrm{km} / \mathrm{s}$ to $8.6 \mathrm{~km} / \mathrm{s}$. Despite a lot of evidence, most of it is unfortunately not ap- 

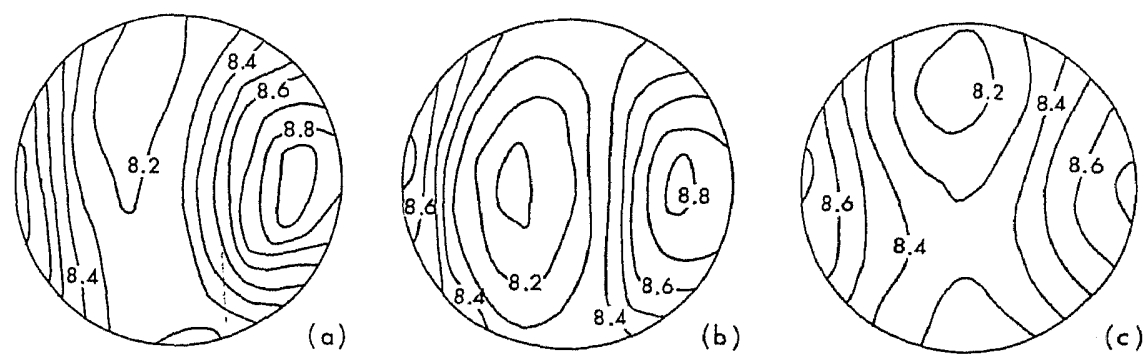

Fig. 5. Examples of equal area projection of $\mathrm{P}$-wave velocities $(\mathrm{km} / \mathrm{s})$ of peridotites from Oman (a), Table Mountain of the Bay of Islands (b), and North Arm Mountain of the Bay of Islands (c). Reproduced from CHRISTENSEN and SMEwING (1981).

plicable to the quantitative inversion for the form of upper mantle materials incorporated with the anisotropy. As we are in the model refinement stage of the anisotropy study, it seems to be a better policy to start from actual olivine rocks, for which the elastic constants and petrofabrics are well investigated. Thereafter, we modify the anisotropy parameters to fit the observation and to integrate various kinds of anisotropy observations into a single anisotropy model, which involves the specific preferred orientation of constituent olivine crystals in the uppermost mantle.

Alpine type dunite from Hidaka (KASAHARA et al., 1968), olivine nodules from Ichinomegata (YoshINO, 1971), the Bay of Islands (CHRISTENSEN and SALISBURY, 1979) and Oman (Christensen and SMEwing, 1981) display a distinct trend of an axial symmetry in which $a$-axis is highly concentrated and $b$-and $c$-axes form a girdly about the $a$-axis. The propagation velocity of the faster among two orthogonally polarized $\mathrm{S}$ waves within the rocks for the above cases is comparatively uniform in directions of the girdle perpendicular to the $a$-axis. These facts seem to be the key to resolve the disparity between the large $P_{n}$ anisotropy and the little azimuthal anisotropy of the Love wave group velocity.

Figure 5 shows typical examples of the equal area projection of the $\mathrm{P}$-wave velocities summarized by CHRISTENSEN and SMEWING (1981). Numerals are the P-wave velocities $(\mathrm{km} / \mathrm{s})$ of peridotites from Oman (a), Table Mountain of the Bay of Islands (b), and North Arm Mountain of the Bay of Islands (c).

Keeping the basic framework of the axial symmetry about the $a$-axis normal to ridge, we attempted a trial and error approach to find a model of the elastic anisotropy in the uppermost mantle which can successfully explain overall features of the patterns of large-scale anisotropy beneath the Pacific Ocean. In a trial and error approach, we proceeded as follows. $C_{11}, C_{22}\left(=C_{33}\right), C_{44}$, and $C_{55}\left(=C_{86}\right)$ were constrained such that $V_{P_{\max }}\left(=\sqrt{C_{11} / \rho}\right)$ and $V_{\mathrm{P}_{\min }}\left(=\sqrt{C_{22} / \rho}\right)$ were in the ranges of $8.55-8.6 \mathrm{~km} / \mathrm{s}$ and $7.85-7.90 \mathrm{~km} / \mathrm{s}$, respectively, and that $V_{\mathrm{SV}_{\max }}$ $\left(=\sqrt{C_{55} / \rho}\right), V_{\mathrm{SV}_{\min }}\left(=\sqrt{C_{44} / \rho}\right)$, and $\Delta V_{\mathrm{SV}}\left(=V_{\mathrm{SV}_{\max }}-V_{\mathrm{SV}_{\mathrm{mIn}}}\right)$ were in the ranges of 
$4.55-4.60 \mathrm{~km} / \mathrm{s}, 4.75-4.80 \mathrm{~km} / \mathrm{s}$, and $0.2-0.3 \mathrm{~km} / \mathrm{s}$, respectively. Incremented by $0.01 \times 10^{12} \mathrm{dyn} \cdot \mathrm{cm}$, many sets of $C_{i j}$ were generated within the ranges. For every set, $C_{12}\left(=C_{23}\right)$ was incremented by $0.01 \times 10^{12} \mathrm{dyn} \cdot \mathrm{cm}$ and azimuthal variation of the QSH in the horizontal plane was calculated by the formula of KASAHARA et al. (1968). When we found a set of $C_{i j}$ in which azimuthal anisotropy of the QSH is less than $0.03 \mathrm{~km} / \mathrm{s}$, we accepted the set of $C_{i j}$ as a final one. Thus, we obtained a model, which we would like to call HDM (Hidaka Dunite Model) in the following, because the dunite from Hidaka first motivated the present authors to undertake this study.

Elastic constants of the HDM are in Table 4, together with those of the SCO and the dunite of Hidaka (KASAHARA et al., 1968). Notation of $C_{i j}$ is the same as LOVE (1944). $\quad X_{1}$-axis (the $a$-axis) is normal to and $X_{2}$-axis is parallel to the ridge. $X_{3}$-axis is vertical. Figure 6 illustrates azimuthal variation of velocities of the quasi body waves within the horizontal $X_{1}-X_{2}$ plane of the HDM.

If we take into account pressure and temperature derivatives of olivine (KUMAZAWA and ANDERSON, 1969) and the pressure and temperature condition at the uppermost mantle, the elastic constants may have an uncertainty of $5 \times 10^{10}$ $\mathrm{dyn} / \mathrm{cm}^{2}$, which is small compared with the order of the amount of the anisotropy pattern and was neglected in this study.

Various kinds of anisotropic observations have been presented so far as regional studies. However, we here assume that the type of preferred orientation of the constituent olivine is age-independent and universal property within the oceanic lithosphere. Then, although agreements are not strict, the anisotropy patterns predicted by the HDM basically agree with the following independent discoveries related to the large-scale anisotropy beneath the Pacific Ocean (also tabulated in Table 5).

\section{$2.2 .1 P_{n}$ anisotropy of $7.9-8.6 \mathrm{~km} / \mathrm{s}$}

The amount of the $\mathrm{P}_{\mathrm{n}}$ anisotropy scatters from $3 \%$ to $8 \%$ (HESs, 1964; MorRIs et al., 1969; RAITT et al., 1969; KEEN and BARRETT, 1971; SNYDSMAN et al., 1975; ShImamura et al., 1983). Reviewing the original data illustrated in these papers, the present authors think that resolution is better in the papers of Morris et al. (1969) and ShIMAmura et al. (1983), which commonly show a large anisotropy of $7.9-8.6 \mathrm{~km} / \mathrm{s}$. We refer to $7.9-8.6 \mathrm{~km} / \mathrm{s}$ hereafter as the amount of the $\mathrm{P}_{\mathrm{n}}$ anisotropy.

\subsubsection{High $S_{n}$ velocity of $\sim 4.8 \mathrm{~km} / \mathrm{s}$}

SHIMAMURA et al. (1977) and KaSAHARA et al. (1983) found fast $\mathrm{S}_{\mathrm{n}}$ velocity of about $4.8 \mathrm{~km} / \mathrm{s}$ in the Northwestern and the Eastern Pacific Ocean. In the same direction $P_{n}$ velocity was not so large $(8.0-8.2 \mathrm{~km} / \mathrm{s})$. This can be interpreted only by the large-scale anisotropy.

\subsubsection{Azimuthal anisotropy of surface waves}

Several percent of the azimuthal anisotropy of the Rayleigh waves and little anisotropy of the Love waves were first found by ForsYTH (1975) and confirmed in the previous section of this paper. 
Table 4. Elastic constants of single crystal olivine (SCO in the text), Hidaka dunite, and the model for the constituent olivine in the uppermost mantle beneath the Pacific Ocean, proposed in this paper.

\begin{tabular}{|c|c|c|c|c|c|c|c|c|c|c|c|}
\hline$C_{11}$ & $C_{22}$ & $C_{33}$ & $C_{12}$ & $C_{23}$ & $C_{18}$ & $C_{44}$ & $C_{55}$ & $C_{\mathrm{fiB}}$ & Density & Material & Reference \\
\hline 3.237 & 1.976 & 2.351 & 0.664 & 0.756 & 0.716 & 0.6468 & 0.7805 & 0.7904 & 3.31 & $\begin{array}{l}\text { single crystal } \\
\text { olivine }\end{array}$ & $\begin{array}{l}\text { KuMAZAWA and ANDERSON } \\
\text { (1969) }\end{array}$ \\
\hline 2.55 & 2.06 & 2.11 & 0.64 & 0.68 & 0.68 & 0.68 & 0.78 & 0.76 & 3.30 & Hidaka dunite & KASAHARA et al. (1968) \\
\hline 2.44 & 2.05 & 2.05 & 0.72 & 0.67 & 0.72 & 0.69 & 0.75 & 0.75 & 3.30 & HDM & this study \\
\hline
\end{tabular}

Unit: $10^{12} \mathrm{dyn} \cdot \mathrm{cm}$ for $C_{i j}$ and $\mathrm{g} / \mathrm{cm}^{3}$ for density

Table 5. Observations related to the large-scale anisotropy in the uppermost mantle and those predicted by the model HDM proposed in this paper.

\begin{tabular}{|c|c|c|c|}
\hline Type of observation & $\begin{array}{l}\text { Predicted by the } \\
\text { model proposed }\end{array}$ & Observation & Reference \\
\hline $\mathbf{P}_{\mathbf{n}}$ anisotropy & $7.88-8.60 \mathrm{~km} / \mathrm{s}$ & $7.9-8.6 \mathrm{~km} / \mathrm{s}$ & MORRIS et al. (1969), SHIMAMURA et al. (1983) \\
\hline High $S_{n}$ velocity & $4.78 \mathrm{~km} / \mathrm{s}$ & $\sim 4.8 \mathrm{~km} / \mathrm{s}$ & $\begin{array}{l}\text { SHIMAMURA et al. (1977), Kasahara et al. } \\
\quad \text { (personal communication) }\end{array}$ \\
\hline \multicolumn{4}{|l|}{ Azimuthal anisotropy } \\
\hline for Rayleigh waves & $4.2 \%$ & $\sim 2 \%$ & FoRsYTH (1975) \\
\hline for Love waves & $0.4 \%$ & $\leq 1 \%$ & FORSYTH (1975) \\
\hline SH-SV anisotropy & $0.11 \mathrm{~km} / \mathrm{s}$ & $\sim 0.15 \mathrm{~km} / \mathrm{s}$ & ForsYTH (1975), SCHLUE and KNOPOFF (1977) \\
\hline $\mathrm{ScS}$ polarization anisotropy & $0.9 \mathrm{~s}$ & $\sim 1 \mathrm{~s}$ & ANDo (1983) \\
\hline
\end{tabular}




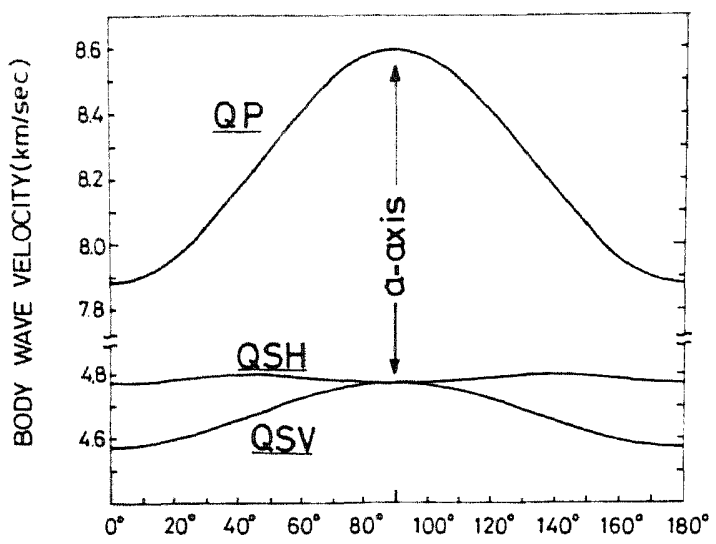

Fig. 6. Azimuthal variations of quasi body waves, QP, QSH, and QSV, within a horizontal plane of the HDM (Table 4) of the possible form for the constituent olivine in the uppermost mantle.

\subsubsection{SH-SV anisotropy of $3-6 \%$}

One of the problems in dispersion analyses of surface waves has been the discrepancy between the mantle Rayleigh and Love waves. The earth model giving a good agreement with Rayleigh wave data did not always give satisfactory results for the Love waves (e.g., Kaminuma (1966) for the Japanese Islands region, and ForsYTH (1975) and Schlue and KNOPOFF (1977) for the Pacific Ocean). Swave velocity deduced from the Love wave data was always larger than that from the Rayleigh waves. This discrepancy is conventionally called the SH-SV anisotropy. The amount of the SH-SV anisotropy is $\sim 0.15 \mathrm{~km} / \mathrm{s}$ (FORSYTH, 1975), which is predicted to be $\sim 0.11 \mathrm{~km} / \mathrm{s}$ by the HDM.

The recognition of the SH-SV anisotropy has been considered to indicate the existense of soft and thin magma pockets (TAKEUCHI et al., 1968). If the anisotropy model HDM is introduced, such magma pockets are not needed to interpret the surface wave dispersion.

\subsubsection{ScS polarization anisotropy}

If we take HDM, it follows that velocity of one of two shear waves propagating in a vertical direction, polarized perpendicular to ridge, should be faster by $\sim 0.2$ $\mathrm{km} / \mathrm{s}$ than that of the other shear wave polarized parallel to ridge. If the lithosphere with a thickness of about $100 \mathrm{~km}$ is subducting under the Eurasian and the South America plates, it yields arrival time difference of about $1 \mathrm{~s}$ between the two shear waves polarized orthogonally to each other, which explains ANDo's (1983) discovery at WWSSN stations, SHK, MAT, BHP, ARE, ANT, and PEL as reproduced in Fig. 7.

DZIEWONSKI and ANDERSON (1981) recently presented the earth model, PREM, inverted from a great deal of seismic data. They derived the transverse isotropy with the symmetrical axis vertical in the outer $220 \mathrm{~km}$ of the mantle, and less pro- 


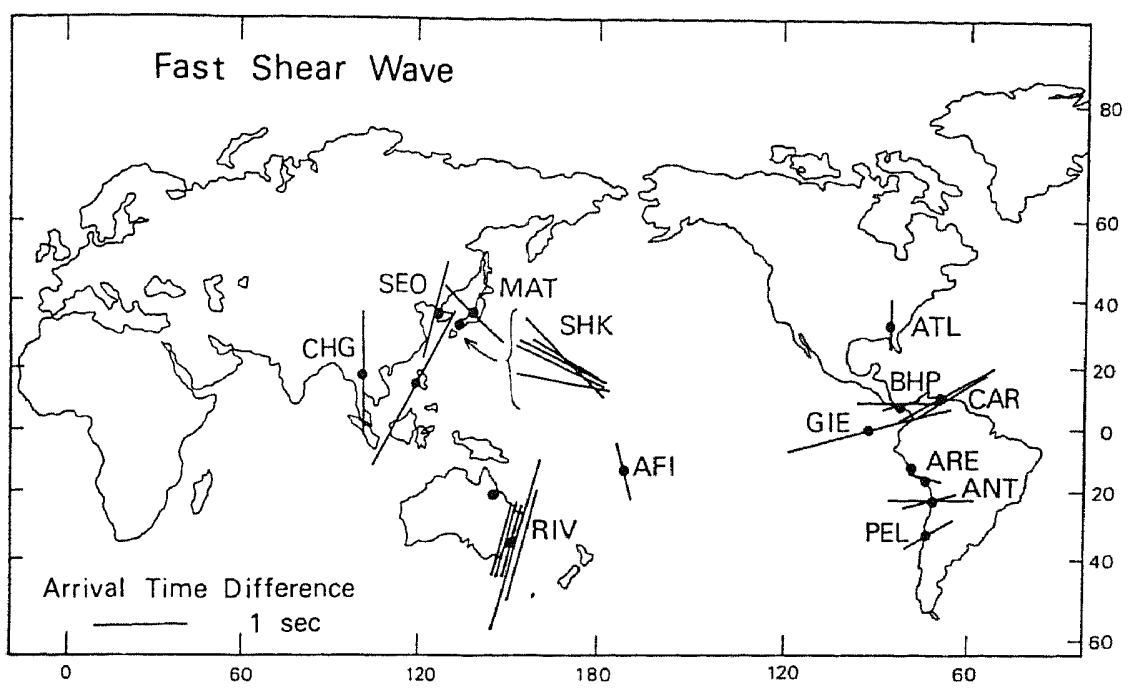

Fig. 7. Arrival time differences between two shear waves of ScS. Bars denote directions of particle motion of one of the two shear waves, which arrived at the stations faster than the other shear wave polarized normal to it. Length of the bar is proportional to the arrival time difference of the two shear waves. Reproduced from ANDO (1983).

nounced distinction between LVZ (low velocity zone) and LID (region above the LVZ). In the outer $220 \mathrm{~km}$ of the mantle, the horizontal $\mathrm{P}$ velocity is smaller by about $4 \%$ that the vertical $\mathrm{P}$ velocity and the horizontal $\mathrm{S}$ velocity is smaller by about $2 \%$ than the vertical $S$ velocity.

In a strict sense, these two anisotropic models are not the same. But the assertion of DzIEWONSKI and ANDERSON (1981) is not about the transverse isotropy. Their data represent an average over many azimuths and azimuthal anisotropy would be averaged out as described in their paper. The present authors would like to emphasize that if we average out the anisotropy pattern of the HDM over azimuths, it yields the same type of anisotropy as the PREM. A large part of the nature of the outer $220 \mathrm{~km}$ of the PREM should be accounted for by the oceanic uppermost mantle, in which the constituent olivine crystals possess the same type of preferred orientation as the HDM.

Christensen and Salisbury (1979) inferred that the olivine nodules found in the Bay of Islands ophiolite complex were mantle materials and that the ophiolite complex was the segment of the paleo-oceanic lithosphere. It was shown in this paper that the model HDM deduced from their olivine nodules can elucidate the overall feature of the observations on the large-scale anisotropy. This fact seems to support the Christensen and Salisbury's suggestion. 


\section{Conclusions}

In the first part of this paper, surface wave group velocities in the eastern part of the Pacific Ocean were obtained. The observed anisotropy pattern of the surface waves is that the Rayleigh waves are the fastest normal to ridge with the azimuthal anisotropy amounting to $3-5 \%$ and that the Love waves show little anisotropy (less than $1 \%$ ), similar to the ForSYTH's (1975) discovery mainly for the Nazca plate. The area investigated is limited to the latitude range $\mathrm{N} 35^{\circ}-\mathrm{S} 40^{\circ}$ and azimuthal coverage of the propagation paths is $\mathrm{N} 60^{\circ} \mathrm{E}-\mathrm{N} 140^{\circ} \mathrm{E}$. However, because isochron of the age of the ocean floors is simply trending north-south in this area, the effects of the lateral heterogeneity due to the ocean floor age could be neglected. This is a very favorable setting to see unobstructed azimuthal anisotropy.

In the second part, we have proposed the HDM (Table 4) for the possible orientation type of the constituent olivine in the uppermost mantle beneath the Pacific Ocean, slightly modifying the elastic constants of the dunite of Hidaka (KasAhara et al., 1968). The basic nature of the model is the axial symmetry about the $a$-axis aligned normal to ridge in the horizontal plane. The HDM thus proposed can basically explain the overall features of the seismological observations on the large-scale anisotropy presented so far (Table 5) in the Pacific Ocean, assuming that the type of preferred orientation is age-independent and universal in the oceanic lithosphere. Though the details may be changed, depending on depth, spreading rate of the oceanic plates, and other factors, the gross nature of the type of preferred orientation may not be changed. Thus, the HDM should be regarded as the starting model and constraint for the general inversion in the next step.

We are grateful to Dr. S. Crampin and Prof. M. Kumazawa for their criticism, helpful comments, and improvement of the manuscript. We further gratefully acknowledge stimulative suggestions and discussions from Drs. J. Kasahara and M. Ando. Dr. M. Ando kindly provided us with a copy of a figure from an unpublished paper. Our thanks are also due to Miss $\mathrm{R}$. Saeki for help in preparing the manuscript.

\section{REFERENCES}

Anderson, D. L. and A. M. DzIEwonski, Uppermantle anisotropy: evidence from free oscillations, Geophys. J. R. Astron. Soc., 69, 383-404, 1982.

ANDo, M., S wave polarization anisotropy as deduced from ScS, Program and Abstracts, Seismol. Soc. Jpn., No. 1, 63, 1983.

Christensen, N. I. and M. H. Salisbury, Seismic anisotropy in the uppermantle: Evidence from the Bay of Islands ophiolite complex, J. Geophys. Res., 84, B9, 4601-4610, 1979.

Christensen, N. I. and J. D. Smewing, Geology and seismic structure of the northern section of the Oman ophiolite, J. Geophys. Res., 86, B4, 2545-2555, 1981.

CRAMPIN, S., A comment on "The early structural evolution and anisotropy of the oceanic upper mantle," Geophys. J. R. Astron. Soc., 46, 193-197, 1976.

Crampin, S. and D. BAmFord, Inversion of P-wave velocity anisotropy, Geophys. J. R. Astron. Soc., 49, 123-132, 1977. 
Dziewonski, A. M. and D. L. Anderson, Preliminary reference Earth model, Phys. Earth Planet. Inter., 25, 297-356, 1981.

Dziewonski, A., S. Bloch, and M. Landisman, A technique for the analysis of transient seismic signals, Bull. Seismol. Soc. Am., 59, 427-444, 1969.

ForsyTH, D. W., The early structural evolution and anisotropy of the oceanic upper mantle, Geophys. J. R. Astron. Soc., 43, 103-162, 1975.

FrancIS, T. J. G., Generation of seismic anisotropy in the upper mantle along the mid-oceanic ridge, Nature, 221, 162-165, 1969.

Hess, H., Seismic anisotropy of the uppermost mantle under oceans, Nature, 203, 629-631, 1964.

Kaminuma, K., The crust and upper mantle structure in Japan. Part 3. An anisotropic model of the structure in Japan, Bull. Earthq. Res. Inst., 44, 511-518, 1966.

Kasahara, J., I. Suzuki, M. Kumazawa, and K. Irda, Anisotropism of S-wave in dunite, Zisin, 21, 229-236, 1968 (in Japanese).

Kasahara, J., S. Nagumo, S. Koresawa, H. Kinoshita, H. AmamiYa, T. Asanuma, and Y. TOMODA, OBSH-air gun survey across the Mendocino Fracture zone (second report), Program and Abstract, the Seismological Society of Japan, No. 2, 203, 1983.

KaWASAKI, I., A method for the near-source anisotropy by the pair-event inversion of Rayleigh eave radiation patterns, Gophys. J. R. Astron. Soc., 71, 395-424, 1982.

KeEn, C. E. and D. L. Barrett, A measurement of seismic anisotropy in the northeast Pacific, Can. J. Earth Sci., 8, 1056-1064, 1971.

Kumazawa, M. and O. L. ANDerson, Elastic moduli, pressure derivatives, and temperature derivatives of single-crystal olivine and single-crystal forsterite, J. Geophys. Res., 74., 59615972, 1969.

Love, A. E. H., A Treatise on the Mathematical Theory of Elasticity, 4th ed., Dover, New York, 1944.

McEvilly, T. V., Central U. S. crust-upper mantle structure from Love and Rayleigh wave phase velocity inversion, Bull. Seismol. Soc. Am., 54, 1997-2015, 1964.

Mitchell, B. J. and G.-K. YU, Surface wave dispersion, regionalized velocity models, and anisotropy of the Pacific crust and upper mantle, Geophys. J. R. Astron. Soc., 63, 497-514, 1980.

Morris, G. B., R. W. RaITT, and G. G. SHOR, Velocity anisotropy and delay time maps of the mantle near Hawaii, J. Geophys. Res., 74, 4300-4316, 1969.

Okada, H., T. Moriya, T. Masuda, T. Hasegawa, S. Asano, K. Kasahara, A. Ikami, H. Aoki, Y. Sasaki, N. Furukawa, and K. Matsumura, Velocity anisotropy in the Sea of Japan as revealed by big explosions, J. Phys. Earth, 26 Suppl., 491-502, 1978.

Peselnick, L., A. Nicolas, and P. R. SteVenson, Velocity anisotropy in a mantle, peridotite from Ivrea zone: Application to upper mantle anisotropy, J. Geophys. Res., 79, 1175-1182, 1974.

Pitman, W. C., III., R. L. LARson, and E. M. Herron, Isochron map and age map of ocean basin, Geol. Soc. Am. Boulder, 1974.

Ratt, R. W., G. G. Shor, T. J. G. Francis, and G. B. Morris, Anisotropy of the Pacific upper mantle, J. Geophys. Res., 74, 3095-3109, 1969.

SCHLUE, J.W. and L. KNopoff, Shear-wave polarization anisotropy in the Pacific Basin, Geophys. J. R. Astron. Soc., 49, 145-166, 1977.

Shimamura, H., T. Asada, and M. Kumazawa, High shear velocity layer in the upper mantle of the western Pacific, Nature, 269, 680-682, 1977.

Shimamura, H., T. Asada, K. Suyehiro, T. Yamada, and I. Inatani, Longshot experiments to study velocity anisotropy in the oceanic lithosphere of the Northwestern Pacific, Phys. Earth Planet. Inter., 31, 348-362, 1983.

Snydsman, W. E., B. T. R. Lewis, and J. MCClaIN, Upper mantle velocities on the Northern Cocos plate, Earth Planet. Sci. Lett., 28, 46-50, 1975. 
TAKeUCHI, H., Y. Hamano, and Y. Hasagawa, Rayleigh- and Love-wave discrepancy and the existence of magma pockets in the upper mantle, J. Geophys. Res., 73, 3349-3350, 1968.

ThATCher, W. and J. N. Brune, Higher mode interference and observed anomalous apparent Love wave phase velocities, J. Geophys. Res., 74, 6603-6611, 1969.

Yoshida, M., Group velocity distribution of Rayleigh waves and two upper mantle models in the Pacific Ocean, Bull. Earthq. Res. Inst., 53, 319-338, 1978.

YosHI, T., Regionality of group velocities of Rayleigh waves in the Pacific and thickening of the plate, Earth Planet. Sci. Lett., 25, 305-312, 1975.

Yoshino, G., Petrofabric study of a peridotite nodule from Ichinomegata, Japan, J. Sci. Hiroshima Univ., 6, 275-308, 1971.

YU, G.-K. and B. J. MitchelL, Regionalized shear velocity models of the Pacific upper mantle from observed Love and Rayleigh wave dispersion, Geophys. J. R. Astron. Soc., 57, 311-341, 1979. 